whence the smaller star was in the south-preceding quadrant. In addition to the authorities for magnitude quoted by Herr Falb, it may be mentioned that both components are found in the last Greenwich Catalogue (1864); the preceding star is there called $8 \mathrm{mag}$, and the following one 7. If we transform the differences of R.A. and N.P.D. in this catalogue into angle and distance, there results for about

\section{I $866^{\circ} 95$ Angle $224^{\circ} \cdot 5$ Distance $36^{\prime \prime} \cdot 4$}

agreeing as closely with Struve's measures as could be expected. The principal or following component of $\Sigma 747$ is Bradley 801 , and its position for the beginning of the present year is in R.A. 5 h. $28 \mathrm{~m} .545^{\circ} 4$, and N.P.L. $96^{\circ} 5^{\prime} 39^{\prime \prime}$; it is $8^{\prime}$ distant from $\iota$ Orionis, on an angle of $225^{\circ}$.

THE VARIABLE STAR R HYDRe,-Observations of this star in southern latitudes are much needed for affording a better insight into the law of variation than we yet possess. That the period has greatly diminished since the time of Maraldi is beyond doubt ; Schönfeld makes it about 500 days for the year 1708, 487 days for 1785 , and 437 days for 1870 . It was pointed out by Argelander that good comparison stars are too low for favourable observation in central European latitudes. According to the formula involving $\mathrm{E}^{2}$ and $\mathrm{E}^{3}$, given in Schönfeld's last catalogue, a maximum would occur on the $25^{\text {th }}$ of February, and the following one falls 1876 , May ro. The minimum, which by Schmidt's observations occurs 200 days before the maximum, will not be observable in the present year. At greatest brightness the star is found to vary from 4.0 to 5.5 . Its position for $\mathrm{J} 875$ is in R.A. I 3 h. $22 \mathrm{~m}$. 53s., and N.P.D. I $12^{\circ} 38^{\prime} \circ$.

WINNECKE'S COMET.-This body is now beyond reach, and it is probable that the observations which have been secured will be few in number. It is nevertheless evident that the elements are very well determined, a very small acceleration which is also indicated in previous revolutions being sufficient to produce an exact agreement between Prof. Oppolzer's calculations and the result of the first Marseilles observation. Reference was lately made to the Vienna astronomer's suspicion of identity of this comet with one of the imperfectly observed comets of 1808 - that which was discovered by Pons on Feb. 6th and seen again on the 9 th. On examining the matter more closely there appears to be strong reasons to doubt this inference, upon which we may enter in a future notice.

THE ZODTACAL LIGHT.-Another conspicuous exhibition of this phenomenon was observable in the neighbourhood of London on the evening of February 25. The sky was very vaporous, and the smaller stars usually visible without a telescope were not discerned, but soon after 8 P.M. the light was quite a marked object in the heavens: if aid not present the lemon tinge which is commonly the case when the sky is clear, but rather resembled the light of the Milky Way, except that it was of much greater intensity. It could not be traced that evening beyond the constellation Musca.

NeW MINOR Planet.-Le Verrier's Bulletin of Feb. 27 announces the discovery of a new member of the minor planet group by Herr Palisa at the Observatory of Pola on the 23rd. Its position at $8 \mathrm{~h}$. $42 \mathrm{~m}$. local time was in R.A. gh. $57 \mathrm{~m}$. 56s., N.P.D. $76^{\circ} 14^{\prime}$. The planet is of the twelfth magnitude.

\section{SCIENCE AT THE NEW PARIS OPERA}

THE New Paris Opera has excited a great deal of attention among all classes, both on the Continent and in England. Every effort has been made to make the building perfect in all respects, and to carry out its construction in harmony with the latest scientific princi- ples. Some recent numbers of La Nature contain a series of articles by $\mathbf{M}$. G. Tissandier on the new building, to show in what manner the principles of science have been rade to conduce to the welfare and comfort of art. A few of the points in these articles we shall bring before our readers, as also some of the illustrations, which have been obligingly lent us by the proprietors of our sister journal. M. Tissandier deals first with the subject of Warming and Ventilation.

It is not astonishing that the ventilation of theatres has been effected in a very incomplete fashion, when we consider the difficulties which stand in the way of a complete solution. "A theatre is composed not of a single compartment, like every other place of assembly, but of three vast contiguous compartments : the hall (or auditorium), the corridors, and the stage, all which, at certain times are separated, at others connected by vast openings. To this first difficulty must be added the action of the lustre, which causes a strong current of sonorous waves towards the ceiling, greatly to the detriment of the acoustics and to the equality of temperature in the various parts of the auditorium. The position of the spectatcrs in tiers rising one above the other along the walls, and not horizontally, adds a new obstacle to the efficacious renewal of the air. Moreover, the conditions of the problem are constantly changing. Thus, before the entrance of the public the heating may have taken place downwards and by the ordinary means; but, once the public have been admitted and the curtain raised, a considerable mass of air, that of the stage, is put into communication with the body of the theatre. Between the acts this communication ceases; but, on the other hand, there are from $I, 000$ to $I, 500$ persons, just so many living stoves, and some hundreds of gas-jets, which heat and gradually vitiate the atmosphere. Hence a change must be introduced in the ventilation; still another change when the curtain is raised; and all this to be modified according to the season." *

At the commencement of the present century the Marquis de Chavannes devised a system, which was tried at Covent Garden Theatre, and which contained the principle of all the methods since invented.

The heating of the stage was effected by steam cylinders, shown at $M$, in Fig. I. Ventilation took place at $\mathrm{N}$ above. The auditorium was heated by the large stove $B$, which by cylindrical pipes sends warm air under the flooring of the boxes and into the staircases. At $R$ the vitiated air of the boxes met, drawn off by the openings A A A. The vitiated air of the body of the theatre drawn upwards by the lustre, reached $\mathrm{O}$, after having traversed the openings $\mathrm{P} P$.

In I 828 a commission, composed of Bérard, Cadet de Gassicourt, Marc, and d'Arcet, was entrusted in Frarce with an investigation into the principles of the ventilation of theatres. Fig. 2 represents the arrangement devised by d'Arcet, who took advantage of the lustre to convey outside the air vitiated by the combustion and by the breath of the audience. The warm air is introduced into the corridors by the openings $\mathrm{C} \mathrm{C} \mathrm{C}$; it enters the auditorium by passing under the flooring of the boxes, in the direction of the arrows. The exit of the air takes place at $U$; it may be regulated above the lustre by means of the movable traps at $T$. It is also accomplished at $V$, by passages which are united in the central chimney.

These systems had serious drawbacks, An attempt at improvement was made in I86I, during the construction of the new theatres in the Place du Chatelet. For the purpose of investigating the question a commission was nominated, presided over by Mi. Dumas, Perpetual Secretary of the Academy of Sciences, and having for reporter General Morin, Director of the Conservatoire des Arts et Métiers. After many experiments and many contra-

\footnotetext{
* "Traité pratique du chauffage et de la ventilation," by V. Ch. Joly.
} 
dictory advices, they fixed on the arrangements advocated since 1860 by M. Trélat.* The system was found, however, to be ineffective.

The question was in this state when M. C. Garnier was called upon to construct the new theatre, which at present justly attracts the attention of all.

The arrangements adopted in the New Opera, without being exactly new, are remarkably improved; if the principles upon which they are founded are almost the same as those referred to above, an effort has been made to apply them under the conditions best calulated to ensure a favourable result.

Of fourteen large stoves fixed in the underground part of the building, some, by means of hot water, heat the administrative department, the stage, and the rooms of the'artistes ; others, by hot air, the auditorium, the green rooms, and the staircases. The daily consumption of these fires has been estimated at 10,000 kilogrammes of coal-nearly ten tons.
The water and air heated by the stoves are distributed by brass pipes, the heating surface of which is about 2,250 square metres, their length nearly five kilometres. Those filled with hot water are contained in grooves in the masonry; the air coming from without circulates around their surface, is heated, and escapes by $65^{\circ}$ orifices.

For the auditorium and its approaches recourse has been had to water-stoves, which give a very consic.erable renewal of air. "The apparatus to the number of ten," says M. Nuitter, "are supplied by twelve furnaces, whose power represents a steam-engine of I20-horsepower. It was necessary to employ apparatus of this power, for as they are only used in the days of performance, they are not kept constantly lighted, and they must rapidly raise the temperature of spaces whose capacity is not less than 90,000 metres. They must, moreover, provide in the auditorium for a renewal of air which may reach 80,000 cubic metres per hour ; thus we must reckon

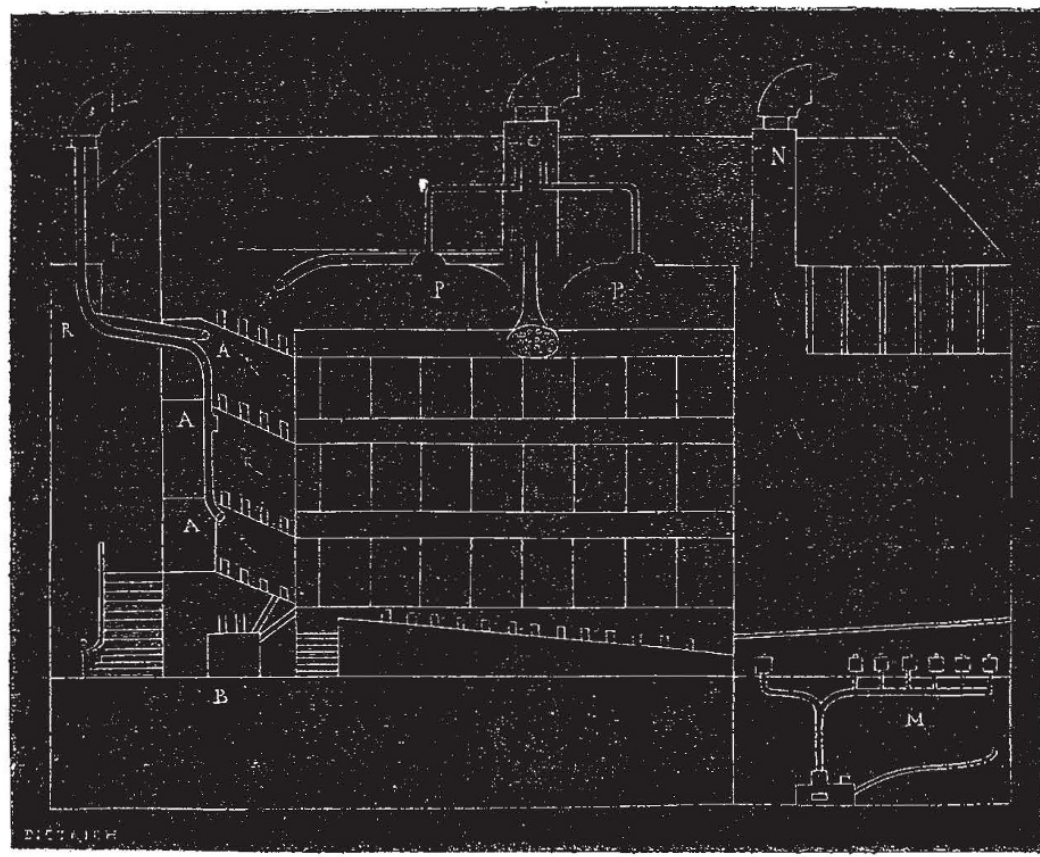

FIG. I,-Ventilation of a Thealre (Chavames' syssem).

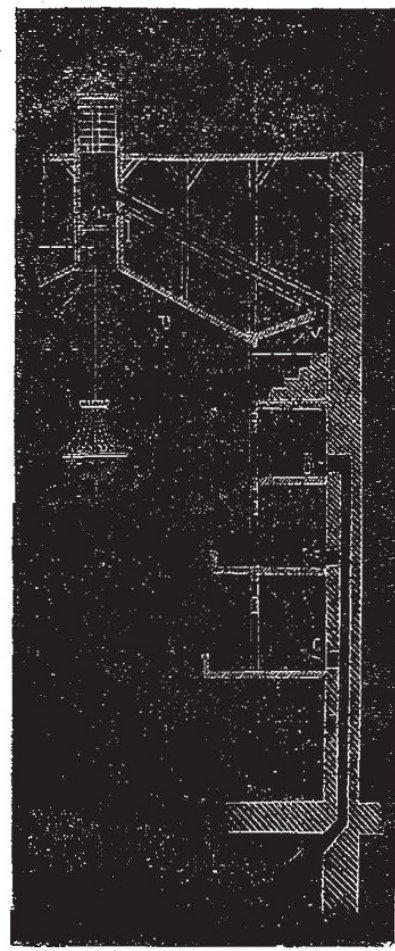

Fig. 2.-The System of d'Arcet. the warm air heaters at from 600 to 700 square metres, and the hot water ones at from 1,200 to $J, 300$ square metres."

Ventilation is effected by means of supplies of air, the openings for which measure from twenty-four to thirty square metres. The cupola of the auditorium is pierced by bulls'-eyes, and is also supplied with openings arranged above the lateral galleries. Fig. 3 shows the cupola seen from above; it shows the vast conduits which carry off the internal air by means of the draught of the lustre. The supplies of air are regulated by thirty-four registers, large valves of $I \frac{1}{3}$ metres long and $\frac{3}{5}$ metre high, placed around the cupola. A large sheet-iron chimney, eight metres in diameter, surmounts the ventilating erection, and leads to the lantern which surmounts the cupola.

Thanks to these excellent arrangements, thanks also to the large proportions of the corridors, there is reason * "La Theatre et l'Architecte." to hope that in the new Opera aëration will be accomplished under satisfactory conditions, and that in this new building the constructors will have approached as nearly as possible to that solution of a problem whose difficulties have been pointed out above.

The lighting of the New Opera has been accomplished with considerable ingenuity. The whole of the gas-pipes represent a length of twenty-five kilometres, on which are adjusted 714 cocks. The dangers attendant on the ordinary method of lighting a stage by naked footlights are well known. The footlights of the New Opera are formed of gas jets with reversed flames, each flame being completely enclosed, so that only the light escapes, the heat being conveyed outside. Each jet is so constructed that if the glass which encloses it is broken, the flame becomes extinguished by an automatic arrangement. In Fig. 4, E is the conducting tube of the gas. It is lighted by raising it at D, above its vertical glass. When it is placed upon 
its glass the flame is drawn downwards by a powerful current of air which circulates in a lower pipe to which

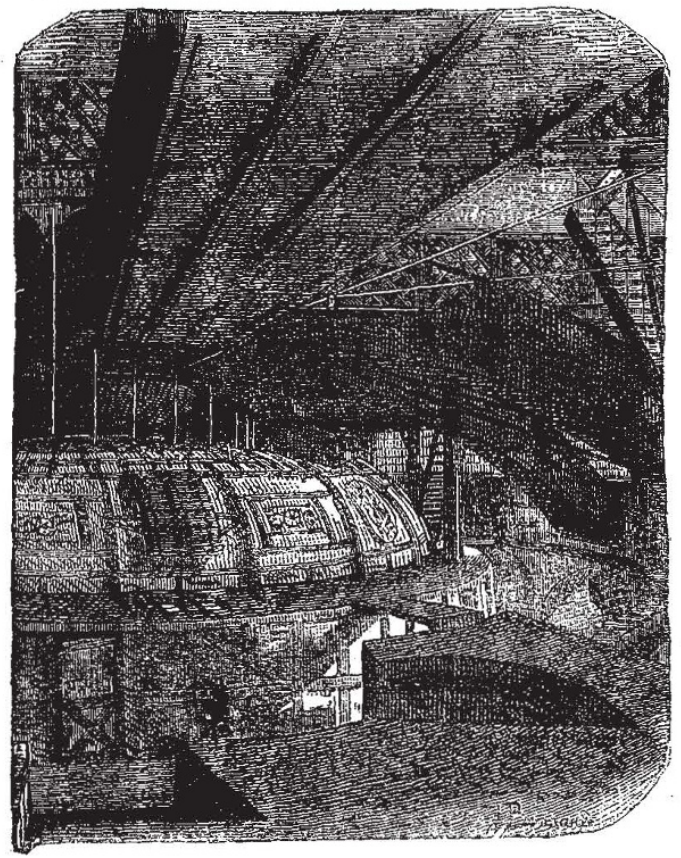

FIG. 3.--Ventilating Apparatus of the New Opera. (From M. Nuitter's work.)

the tube $B$ is fitted. Owing to the draught the burnes does not become heated, and the hand may be placed

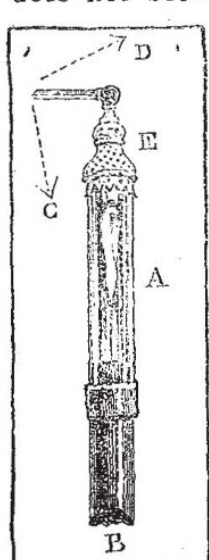
Fig. 4.-Gas-jet, with reversed flame,
used in the footlights used in the footlights
of the New Opera the use made of electricity, which we shall describe in another article.

\section{(To be continued.)}

\section{ENGLISH GOVERNMENT ECLIPSE EXPE- DITION, 1875}

INSTRUCTIONS TO OBSERVERS.*

I.-Spectroscopic Observations-Objects to be attained.

THE objects to be attained are mainly the determination, so far as may be possible, of the chemical constitution of the chromosphere and of the coronal atmo-

* Drawn up by the Eclipse Committee of the Royal Society. sphere; of the height to which the various vapours extend from the photosphere, and of the order in which they thin out. It is anticipated that the chromosphere, at all events, may be very rich in ultra-violet rays. The solar spectrum has already been photographically compared with metallic vapours from $G$ some distance outwards. The operations, therefore, will be mainly photographic, glass being employed as little as possible to produce the necessary dispersion, and replaced by quartz. The attack is twofold, spectroscopes being used in conjunction with telescopes for obtaining line spectra, and prismatic cameras being employed for the purpose of obtaining images of the chromosphere and coronal atmosphere built up by the rays emitted by its various constituents. The prismatic camera will probably give the best results with regard to the height and order of the various layers, while the general nature of the spectrum beyond $\mathrm{H}$, i.e. whether it is continuous, channelspaced, or lined, will be best determined by the ordinary spectroscopes.

\section{Adjustment of Spectroscopes.}

Take out camera, and determine focal point for blue rays by receiving image of sun on ground glass, and by using solution of sulphate of copper in ammonia in front of object-glass. (The strength of solution to be determined beforehand such that no light less refrangible than $G$ should pass at all, and that the centre of gravity of spectrum is $\mathrm{H}$, or outside it.)

To determine focus of collimator, reinsert camera and move sliding portion of collimator attached to slit-plate till the lines of the spectrum at or outside $\mathrm{H}$ are clearly defined.

All prisms to be set for minimum deviation of $\mathrm{H}$.

To find proper distance of slit-plate from telescope, throw image of sun on, so as to cover half the slit, and adjust the spectroscope to such a distance that the boundary of the spectrum of the photosphere at $\mathrm{H}$ is perfectly hard.

Photographs should be employed for ascertaining the focus; the slits to be clean, and adjusted so that at least three lines be seen between the two H's. No photograph need be examined. which will not bear a mag. nifying power of ten times. It must be remembered that a difference of I-roooth of an inch is of importance in such adjustments. The best definition with the dispersion employed will be attained when the line in the middle between the $H$ lines is seen double.

The hardness of the sun's limb to be deternined photographically in the same manner.

If power to incline the plate is obtained, the part of the plate to receive the more refrangible rays will, of course, be nearer to objective of camera, as in the case of all nonachromatic lenses. The angle to be determined by experiment. The spectrum should fall on the plate so that $\mathrm{G}$ falls close to one edge, the central and other portions of the plate being reserved for the more refrangible end of the spectrum.

Care must be taken that the axes of the collimator and of the telescope be coincident.

\section{Adijustment of Prismatic Camera.}

This instrument is to be adjusted like an ordinary spectroscope by means of collimator placed in front of its prism. By application of external collimator, the prism is to be set to minimum deviation of $\mathrm{H}$, the hydrogen line near $G$ falling near one edge of the plate.

Before this instrument is put on the telescope, the prism thus adjusted should be taken off and perfect parallelism of the tubes obtained by observing the images of the sun or star.

The subsequent inclination of the two axes will be determined by taking photographs of spectrum with or without a collimator, so that ring corona near $G$ will be the least refrangible portion of spectrum on plate, while the sun falls on the steel plate of the telescope to which 